Original Research Article

\title{
Prescription pattern of antibiotics in paediatric inpatients at a tertiary care hospital in North East India
}

\author{
Sayeri Dutta*, Abhishek Bhattacharjee, N. Meena Devi
}

Department of Pharmacology, Regional Institute of Medical Sciences, Imphal, Manipur, India

Received: 23 July 2017

Accepted: 22 August 2017

*Correspondence to:

Dr. Sayeri Dutta,

Email: dutta.sayeri@gmail.com

Copyright: (C) the author(s), publisher and licensee Medip Academy. This is an openaccess article distributed under the terms of the Creative Commons Attribution NonCommercial License, which permits unrestricted noncommercial use, distribution, and reproduction in any medium, provided the original work is properly cited.

\begin{abstract}
Background: Paediatric antibiotic prescription is a major concern in terms of public health since infections are the most frequent cause of childhood disease. The aim of this hospital-based cross sectional study was to assess the pattern of antibiotic use in the paediatric ward of RIMS hospital, Manipur, India.

Methods: A retrospective study of six months duration was carried out for the month of October 2016 to March 2017. A total number of 200 patients case sheets were utilized for our study from paediatric in-patients department of RIMS hospital, Manipur. The data collected was then analysed for various prescribing indicators as laid down by world health organisation (WHO) for analysis of drug use parameters.

Results: The mean age of paediatric patient was 2.1 years. The average number of drugs per encounter was 5.14. The average number of antibiotic per patient was 2.11 . In present study antibiotic were $41 \%$ of total drugs prescribed. Most common prevalence of disease among study patients sample was acute gastroenteritis. The most commonly prescribed antibiotic was Ceftriaxone followed by Amikacin. In present study $8.2 \%$ of antibiotics were prescribed in generic name. Polypharmacy was evident from the study.

Conclusions: Antibiotic prescribing in children is relatively high in RIMS, Imphal, Manipur. Prescription of broad-spectrum antibiotics though has increased demonstrably which $\mathrm{h}$ may result in development of bacterial resistance; however, development of guidelines for antibiotic prescription and use of appropriate drugs for the disease can result in minimizing the unfavourable use of antibiotics in children.
\end{abstract}

Keywords: Antibiotic prescription, Cross-sectional study, Paediatric, Polypharmacy

\section{INTRODUCTION}

Antibiotics are the key drugs for treatment of infections and are among the most commonly prescribed drugs in Pediatrics department. ${ }^{1}$ Their indiscriminate use increases the risk of bacterial drug resistance and thus has prompted the need to use antibiotics judiciously in pediatric practice. $^{2}$

Studies reported that $50 \%$ to $85 \%$ of children receive antibiotics in developed and developing countries. ${ }^{3}$ Rational antibiotic prescription is very important to avoid multiple drug resistance, treatment failure, noncompliance and increase in cost of treatment. ${ }^{4}$

Irrational prescribing is a global problem. The rationality of prescribing pattern is of utmost importance because bad prescribing habits including misuse, overuse and underuse of medicines can lead to unsafe treatment, exacerbation of the disease, health hazards, and economic burden on the patients and wastage of resources. Examples of irrational use of medicines include: poly-pharmacy, inadequate dosage, and use of antimicrobials even for non-bacterial infections, excessive use of injections when oral forms are available and inappropriate, self-medication and noncompliance to dosing regimes. ${ }^{5}$ 
Several professional societies have issued guidelines designed to reduce the use of antibiotics worldwide by means of various control strategies. Detailed knowledge of antibiotic prescription pattern is important before policies and measures can be implemented. ${ }^{6}$

Drug prescribing is a skill that needs to be refined on a continuing basis. It reflects that professional's skills and attitude toward diagnosis of an ailment and selection of appropriate treatment. In view of this, it is important to do study the pattern of prescribing in pediatrics patients on continuous bases. $^{7}$

\section{METHODS}

The objective of the study was to assess the pattern of Antibiotic Use in the Paediatric ward of RIMS, Imphal, Manipur, Northeast India.

The study was a quantitative, observational, crosssectional type of study done in a RIMS Hospital, Imphal, Manipur, October 2016 to March 2017.

The case files were retrieved from the Medical record section and the data were noted in a preformed pro forma. The sample size of the study was 200 patients from 1-12 years of age. Neonates, OPD cases, and HIV positive cases were excluded.

The information retrieved from the case notes included bio-demographic data, diagnoses, list of prescribed drugs and their routes of administration. The following drug use indicators were assessed using the WHO guidelines on investigation of drug use in health care facilities:

- Average number of drugs per prescription,

- Percentage of encounters with antibiotics,

- Percentage of drugs prescribed by generic name,

- Percentage of drugs prescribed from essential drug list

- Percentage of encounters with injection.

Intravenous fluids, blood transfusion and nutritional preparations were not included in the study.

\section{RESULTS}

In our study, we found out that mean age of paediatric patients was 2.1 yrs. More number of male patients were admitted $(60.74 \%)$ as compared to females (39.2\%). The average number of drugs per encounter was 5.14.

All patients were exposed to more than one drug. The average number of antibiotic per patient was 2.11. The demographic characteristics of patients were noted from the data (Table 1).

Most common prevalence of disease among study patients sample was acute gastroenteritis followed by pneumonia and Enteric fever (Table 2).
Table 1: Demographic characteristics of patients.

\begin{tabular}{|ll|}
\hline Age & Number \\
\hline 1 month- 1 year & $40.5 \%(81)$ \\
\hline 1 year- 5 year & $44 \%(88)$ \\
\hline 5-12 year & $15.5 \%(31)$ \\
\hline Gender & \\
\hline Male & $60.74 \%$ \\
\hline Female & $39.2 \%$ \\
\hline
\end{tabular}

Table 2: Most common diagnosis encountered.

\begin{tabular}{|ll|}
\hline Acute gastroenteritis & $\mathbf{6 6 . 6 \%}(\mathbf{1 3 3})$ \\
\hline Enteric fever & $9.62 \%(19)$ \\
\hline Pneumonia & $9.62 \%(19)$ \\
\hline Bronchilotis & $5.18 \%(10)$ \\
\hline LRTI & $3.7 \%(7)$ \\
\hline Bacterial Meningitis & $1.4 \%(3)$ \\
\hline
\end{tabular}

Our results showed tendency of polypharmacy with maximum number of prescriptions. Most of the paediatric patients were prescribed 2 antibiotics $(80 \%)$.

The prescriptions were further analysed for various prescribing indicators as laid down by WHO (Table 3).

The number of generic drug prescribed were only $8.2 \%$.

Table 3: Various prescribing indicators.

\begin{tabular}{|ll|}
\hline Prescribing indicators & Details \\
\hline $\begin{array}{l}\text { Number of prescriptions with generic } \\
\text { drugs }\end{array}$ & $8.2 \%$ \\
\hline Number of antibiotics per prescription & 2.11 \\
\hline Total number of drugs & 5.14 \\
\hline Number of fixed drug combinations & $148(74 \%)$ \\
\hline Number of injectables per prescription & $44 \%$ \\
\hline $\begin{array}{l}\text { Drugs from essential drug list (WHO } \\
\text { 2013) }\end{array}$ & $60 \%$ \\
\hline
\end{tabular}

The most common antibiotc given was Ceftriaxone followed by Amikacin (Table 4).

In most of the prescriptions, antibiotics were prescribed by Parenteral route $(75 \%)$.

Table 4: Most common antibiotics received.

\begin{tabular}{|ll|}
\hline Antibiotics & Number of prescription \\
\hline Ceftriaxone & 115 \\
\hline Amikacin & 89 \\
\hline Metronidazole + Ofloxacin & 86 \\
\hline Norfloxacin + Tinidazole & 62 \\
\hline Polymyxin E & 12 \\
\hline Gentamycin & 10 \\
\hline Netilmicin & 10 \\
\hline
\end{tabular}




\section{DISCUSSION}

The present study was carried out by analyzing 200 inpatients case sheets of paediatric patients randomly selected from medical records over 6 months period. There was preponderance of male patients in our study which could be the reflection of general pattern of sex distribution in the population of the vicinity of study site. This finding is also seen in other similar previous studies. ${ }^{1,8}$ More number of paediatric patients admitted in the wards belonged to $1-5$ years of age (44\%) suggesting that children of these age group are more susceptible for infections. Average number of drugs per person is an important index of prescription audit. Mean number of drugs per prescription should be kept as low as possible. The WHO recommends that the average number of drugs per prescription should be less than two. ${ }^{9}$ Average number of drugs prescribed per case was 5.14. It could be due to in-patients nature of the study. Higher figures (polypharmacy) always lead to increased risk of drug interaction, adverse effects, development of bacterial resistance, increased hospital cost.

Multiple antibiotics were prescribed in most of the prescriptions and the average number of antibiotics per prescriptions were 2.11 , both of which are more as compared to previous similar studies like Choudhury DK, Gupta K et al and Arute JE studies. ${ }^{1,8,10}$ In Palikhe N study $79 \%$ of patients received multiple of antibiotics. ${ }^{11}$ In present study percentage of multiple antibiotics prescribed is more and this indicates delay of diagnosis or selection of inappropriate antibiotic without prior culture sensitivity testing. This could also be due to more severe form of diseases which failed to respond to single antibiotic treatment. Most of the antibiotic prescriptions were based on clinical diagnosis, not on culture sensitivity test report. It is important to obtain proper specimen, examination and culture for selection of proper antibiotics. This can prevent development of antibiotic resistance, reduces the side effects of drugs and also decrease the cost of treatment. ${ }^{12}$ Ceftriaxone and Amikacin were most commonly prescribed antibiotics against diseases like AGE, LRTI and URTI. This could be due to their effectiveness in these conditions as well as the routine availability of these drugs in our setup. Ceftriaxone was commonly used in cases of meningitis and enteric fever. These results were comparable with other studies like Choudhury DK and Gupta K et al and Van Houten MA study. ${ }^{1,8,13}$ In present study $75 \%$ of antibiotics were administered by parenteral route. WHO recommends lesser use of injection as it helpful in reducing the cost of treatment and its disadvantages. ${ }^{1}$ But some factors facilitate the use this route. In oral dosage forms the most commonly used dosage form was syrup. Children are comfortable with the dosage form like syrup and drops compared to tablets and capsules. It increases compliance and helps in completing the treatment regimen.

In this study antibiotic prescription pattern was not rational as there is polypharmacy, overuse and inappropriate use of antibiotics without prior culture sensitivity testing, excessive Parenteral use of antibiotics administration. Though a conclusive inference could only be made after analysing larger number of cases. Less number of samples and single study site were limitations of our study. However, keeping in context the results of this study we recommend that the professional organizations should take up projects to increase the awareness about antibiotic use among the practicing physicians through systematic approach and latest information in order to check the emerging problem of antibiotic resistance.

\section{ACKNOWLEDGEMENTS}

Authors would like to thank all the faculties of Pharmacology Department and their co-authors for helping them to carry out this study.

Funding: No funding sources Conflict of interest: None declared

Ethical approval: The study was approved by the Institutional Ethics Committee (A/206/REB/Prop(SP)27/3/2017)

\section{REFERENCES}

1. Choudhury DK, Bezbaruah BK. Antibiotic Prescriptions Pattern in Paediatric In-Patient Department Gauhati Medical College and Hospital, Guwahati. J App Pharm Sci. 2013;3(08):144-8.

2. Sharma M, Eriksson B, Marrone G, Dhaneria S, Lund borg CS. Antibiotic prescribing in two private sector hospitals; one teaching and one non-teaching: A crosssectional study in Ujjain, India. BMC Infectious Diseases. 2012;12(1):155.

3. Paluk E, Katzentein D, Frankish CJ, Herbert CP, Miler R, Speert D, et al. Prescription practices and attitudes toward giving children antibiotics. Can Fam Physician. 2001;47:521-7.

4. Sekharan G, Parasuraman GK, Katta A. Assessment of prescribing practices among urban and rural general practitioners in Tamil Nadu. Indian $\mathbf{J}$ of Phar. 2013;45(3);252-7.

5. Abidi A, Gupta S, Kansal S, Ramgopal. Prescription auditing and drug utilization pattern in a tertiary care teaching hospital of western UP. Int $\mathbf{J}$ Basic Clin Pharmacol. 2012 Dec;1(3):184-90.

6. Marlies A, Van Houten, Marian Laseur, Jan LL. Kimpen. Shift in antibiotic prescribing patterns, in relation to antibiotic expenditure in pediatrics. European Journal of pediatrics, 1998; June, 157(6):479-81.

7. Pramil T, Rajiv A, Gaurav G. Pattern of prescribing at a pediatric outpatient setting in northern India. Indian Journal of Pharmacy Practice, 2012;Jan-Mar;5(1):404.

8. Gupta K. Prescribing Pattern of Antibiotics in the Department of Pediatrics in a Tertiary Care Medical College Hospital in Northern India. Asian Journal of 
Medical Sciences (E-ISSN 2091-0576; P-ISSN $2467-$ 9100). 2014 Jun 23;5(4):69-72.

9. WHO. How to investigate drug use in health facilities: selected drug use indicators, Geneva: world health organization 2010: WHO/DAP/93.

10. Arute JE, Adigom DO, Erach PO, Eichie EF, Eniojukan JF. Antibiotic prescription pattern in the paediatric ward of a tertiary health care facility in southern Nigeria. Journal of Pharmaceutical and Allied Sciences. 2011;8(3):34-42.

11. Palikhe, N. Prescribing Pattern of Antibiotics in Paediatric Hospital of Kathmandu Valley. Journal of Nepal Health Research Council. 2004;2(2):31-6.
12. Leung E, Weil E D, Raviglione M, Nakatani H. The WHO policy package to combat antimicrobial resistance. Bulletin of the WHO. 2011;89:390-2.

13. Van Houten MA, Luinge K, Lasuer M, Kimpen JL. Antibiotic utilization for hospitalized paediatric patients. Internal J of Antimicroagents, 1998;10:1614.

Cite this article as: Dutta S, Bhattacharjee A, Devi MN. Prescription pattern of antibiotics in paediatric inpatients at a tertiary care hospital in North East India. Int J Basic Clin Pharmacol 2017;6:2384-7. 